\title{
Sistem Informasi E-Procurement Untuk Mewujudkan Proses Pelelangan Barang dan Jasa Yang Transparan, Efisien dan Akuntable
}

\author{
Khusnul Qotimah \\ Program Studi S2 Pendidikan Teknologi dan Kejuruan, Universitas Negeri Surabaya \\ khusnulqotimah16070895003@mhs.unesa.ac.id
}

\begin{abstract}
Abstrak - E-procurement adalah suatu proses pengadaan barang dan jasa secara online melalui internet, dengan adanya eprocurement diharapkan proses akan menjadi transparan dan dapat mudah diawasi oleh peserta lelang dan masyarakat sehingga proses pengadaan barang dan jasa akan adil (fair). Sistem Informasi E-Procurement adalah Sistem Informasi berbasis web yang digunakan sebagai sarana untuk membantu proses pengadaan barang dan jasa mulai dari proses pelelangan, pendaftaran pelelang, data pelelangan, data penawar, proses penawaran hingga proses seleksi pemenang. Ada 4 pengguna dalam Sistem Informasi E-procurement ini, yaitu : Admin, Pelelang, Penawar dan Tamu.

Pemilihan penyedia barang dan jasa dengan menggunakan sistem e-Procurement diharapkan untuk mewujudkan tujuan pelaksanaan pengadaan barang dan jasa pemerintah yang efektif, efisien, transparan, adil atau tidak diskriminatif dan akuntabel.
\end{abstract}

Kata Kunci - E-procurement, web, pengadaan, pelelangan, penawaran

\section{Pendahuluan}

\section{A. Latar Belakang Masalah}

Proses pengadaan barang dan jasa adalah proses yang memerlukan transparansi, efisisensi dan akuntabel dalam setiap tahapnya mulai dari pengadaan barang, pelelangan, penawaran sampai penentuan pemenang tender. Pada

era globalisasi saat ini, instansi perlu melakukan inovasi dalam meningkatkan kinerja, dengan memakai teknologi internet sebagai sarana dalam mendukung proses pengadaan barang dan jasa.

Kegiatan pengadaan atau disebut procurement merupakan kegiatan instansi dalam pengadaan barang mulai dari pelelangan, penawaran sampai penentuan pemenang.

Kekurangan dari proses pengadaan barang dan jasa secara manual adalah jika permintaan terhadap barang/material besar. Namun, dalam penanganan pengadaaan barang/materialnya memakan waktu yang lama, sehingga dapat menghambat efisiensi pengadaan barang.

Disamping itu juga, proses pengadaan barang/material nya kurang efisien dari segi penggunaan material, seperti penggunaan media telepon, fax untuk menghubungi supplier, juga pemakaian kertas untuk pencetakan form pemesanan dan pembelian barang.

Dari segi efisiensi waktu, proses pelelangan secara manual juga kurang efisien. Penawaran barang yang harus dilakukan secara face to face, pengiriman form pemesanan dan pembelian barang dan surat menyurat seperti pakta integritas. Serta negosiasi dari pihak pelelang dan penyedia barang dan jasa tentu memakan waktu yang lama yang menyebabkan proses pelelangan ini tidak segera terealisasi.

Atas dasar permasalahan di atas, maka dibangunlah sebuah sistem Sistem Informasi e-procurement.

Dengan Adanya Sistem Informasi system pengadaan berbasis web, akan membantu instansi/perusahaan dalam meningkatkan efisiensi waktu dalam pengadaaan barang/material, membantu perusahaan mencatat seluruh transaksi yang terjadi selama proses pengadaan barang dan juga mengurangi kemungkinan terjadinya kesalahan pencatatan pada saat terjadinya transaksi.

\section{B. Rumusan Masalah}

Bagaimana merancang dan membuat Sistem Informasi e-procurement sebagai sarana pelelangan barang dan jasa yang transparan, efisien dan akuntable?

\section{Tujuan}

Tujuan dari penelitian ini adalah merancang dan membuat Sistem Informasi e-procurement untuk mewujudkan proses pelelangan barang dan jasa yang transparan, efisien dan akuntable..

\section{TINJAUAN PUSTAKA}

\section{A. Definisi Lelang}

Lelang adalah proses membeli dan menjual barang atau jasa dengan cara menawarkan kepada penawar, menawarkan tawaran harga lebih tinggi, dan kemudian menjual barang kepada penawar harga tertinggi.

Procurement adalah semua aktivitas yang melibatkan akivitas mendapatkan barang meliputi pembelian, juga kegiatan logistic ke dalam seperti, transportasi barang masuk dan penyimpanan di gudang sebelum barang tersebut digunakan [2].

Sedangkan E-procurement adalah kegiatan pembelian antara pembeli dan pemasok yang terintegrasi mulai dari permintaan pembelian, pembelian, pengiriman hingga pembayaran yang berbasiskan web dengan memanfaatkan internet [4].

E- procurement dibagi menjadi 2 proses yaitu Pre-Purchase dan After Purchase Activities dengan aktivitas yang berbeda. 
Dalam Pre-Purchase Activities terdapat 5 sub aktivitas yaitu : 1) Search vendor and products : pencarian vendor dan produk yang dilakukan oleh perusahaan, aktifitas pencarian ini bisa di dapat melalui e-catalogs, brosur, atau melalui telepon, 2) Qualify vendors : memilih vendor mana yang kira - kira dapat diajak bekerjama dengan melakukan research keuangan, stabilitas dari vendor tersebut [8].

\section{B. Basis Data}

Basis data atau database adalah sekumpulan data yang saling berhubungan yang menjelaskan aktivitas suatu organisasi atau dapat juga didefinisikan sebagai sekumpulan data yang saling berhubungan dan menjadi bagian dari suatu Data Base Management System. Elemen penting di dalam sistem basis data adalah basis data sebagai inti dari sistem basis data, perangkat lunak (software) sebagai perancangan dan pengelolaan basis data, perangkat keras (hardware) sebagai pendukung operasi pengolahan data, manusia (brainware) yang mempunyai elemen penting dalam sistem tersebut [7].

Basis data terdiri dari satu atau lebih tabel yang yang saling berhubungan. Anda atau user mempunyai wewenang untuk mengakses data tersebut, baik untuk menambah, mengubah atau menghapus data yang ada di dalam tabel tersebut [3].

Saat ini banyak perangkat lunak database yang menggunakan SQL sebagai perintah untuk mengkses data. Beberapa diantaranya: DB2, Ingress, Informix, ORACLE, Ms. Acces, MySQL, PostgreeSQL, Rdb, Sybase [1]. Dalam Sistem Informasi E-procurement ini kami menggunakan MySQL .

\section{Pemrograman Web}

Membahas mengenai web tentunya tidak terlepas dari HTML (HyperText Markup Language), yaitu suatu bahasa yang menggunkaan tanda-tanda tertentu (disebut sebagai Tag) untuk menyatakan kode-kode yang harus ditafsirkan oleh browser agar halaman tersebut dapat ditampilkan secara benar. Dokumen HTML sebenarnya hanya berupa dokumen teks biasa [6].

HTML kependekan dari Hyper Text Markup Language. Dokuman HTML adalah file teks murni yang dapat dibuat dengan editor teks sembarang. Dokumen ini dikenal sebagai web page. Dokumen HTML merupakan dokumen yang disajikan dalam browser web surfer. Dokumen ini umumnya berisi informasi atau interface Sistem Informasi di dalam Internet.

HTML merupakan bahasa yang digunakan untuk menulis halaman web. Biasanya mempunyai ekstensi “.htm”, ".html”, atau ".shtml". HTML tersusun atas tag-tag, digunakan untuk menetukan tampilan dari dokumen HTML yang ditejemahkan oleh browser. Tag HTML tidak case sentive, jadi bisa menggunakan $<$ HTML $>$ atau $<$ html $>$ Keduanya menghasilkan output yang sama.

\section{PERANCANGAN DAN ANALISIS}

Jenis penelitian yang digunakan dalam penelitian ini adalah penelitian dan pengembangan. Penelitian dan pengembangan ini menggunakan metode Research and Development (R\&D) dengan memanfaatkan E-Procurement berbasis web. Research and Development (R\&D) adalah metode penelitian yang digunakan untuk menghasilkan produk tertentu, menguji keefektifan produk tersebut [5].

\section{A. Kebutuhan Perangkat Keras}

Sistem Informasi e-procurement memerlukan hardware pendukung diantaranya :

1) Satu buah komputer server,

2) Satu buah personal komputer/laptop minimal pentium 4,

3) Jaringan internet.

\section{B. Kebutuhan Perangkat Lunak}

Sistem Informasi e-procurement ini memerlukan software pendukung diantaranya :
1) XAMPP,
2) $\mathrm{PHP}$
3) $\mathrm{MySql}$,
4) Web Browser

\section{Perancangan Sistem berdasar Pengguna}

Beberapa pengguna sistem Sistem Informasi ini diantaranya yaitu :
1) Pelelang
2) Penawar
3) Admin
4) Tamu

Berikut adalah Flow Chart dari masing-masing pengguna system.

1) Pelelang :

Keterangan Pelelang:

a) Pelelang melakukan registrasi untuk menggunakan Sistem Informasi ini

b) Setelah di validasi, pelelang melakukan log in dengan username dan password

c) Kemudian pelelang melakukan uploading barang yang akan dilelang

d) Pelelang memberikan informasi pelelangan barang tersebut

e) Pelelang melakukan pengecekan terhadap penawaran yang masuk.

f) Jika ada penawaran yang masuk maka pelelang melakukan penentuan untuk mementukan siapa yang menjadi pemenang secara independen

g) Jika tidak ada penwaran yang masuk, maka pelelang melakukan konfirmasi ke Admin untuk memberikan informasi apakah pelelangan dilanjutkan atau tidak

h) Admin melakukan Logout untuk mengakhiri. 


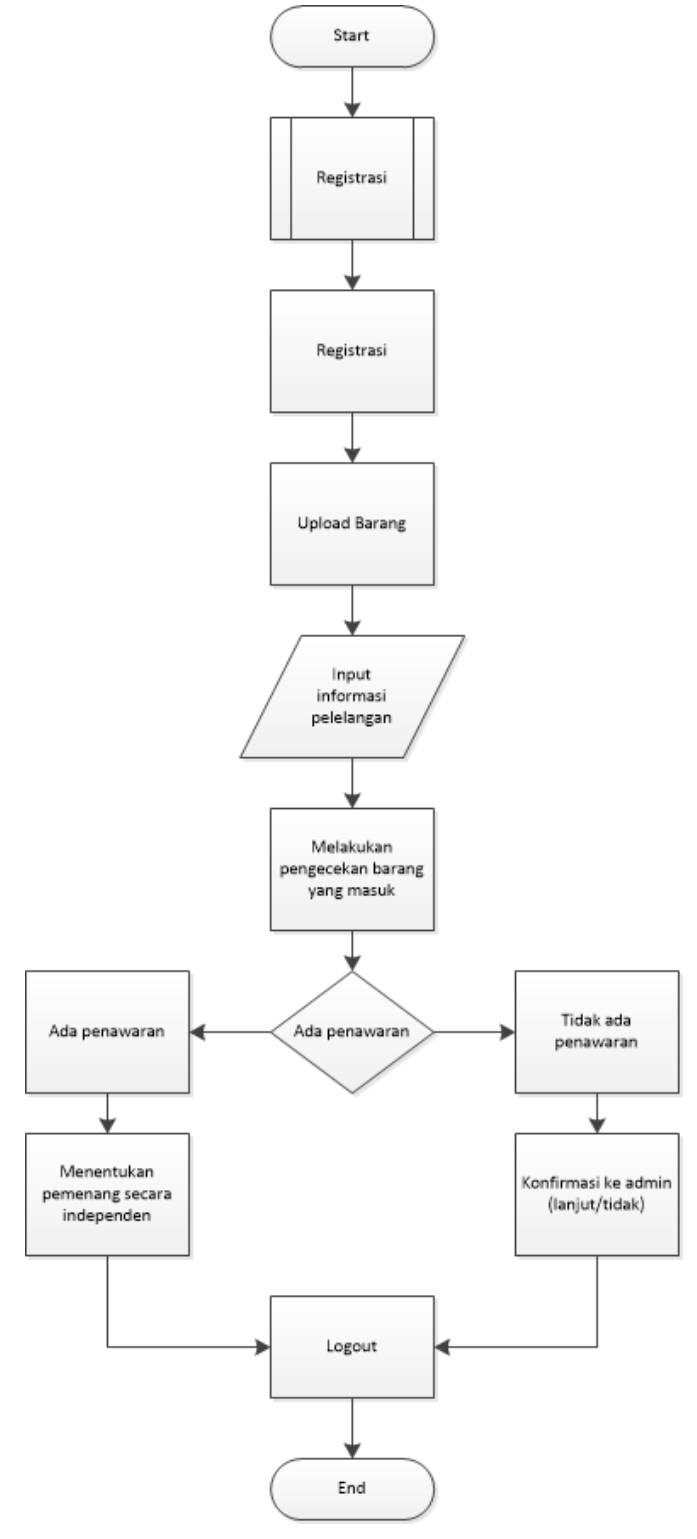

Gambar 1. Flowchart Pelelang

2) Penawar

Keterangan Penawar:

a) Penawar melakukan registrasi untuk menggunakan Sistem Informasi ini

b) Setelah di validasi, penawar melakukan log in memasukan username dan password

c) Kemudian penawar melakukan Seaarching barang yang akan ditawar

d) Penawar melakukan penawaran terhadap barang tersebut

e). Kemudian penawar melakukan pengecekan terhadap penawaran yang masuk.

f) Jika harga tawaran yang masuk lebih rendah, maka penawar boleh melakukan penawaran kembali barang tersebut g) Jika harga tawaran penawar adalah yang tertinggi, maka penawar dapat melakukan komunikasi independen terhadap pelalang

h) Penawar melakukan log out untuk mengakhiri.

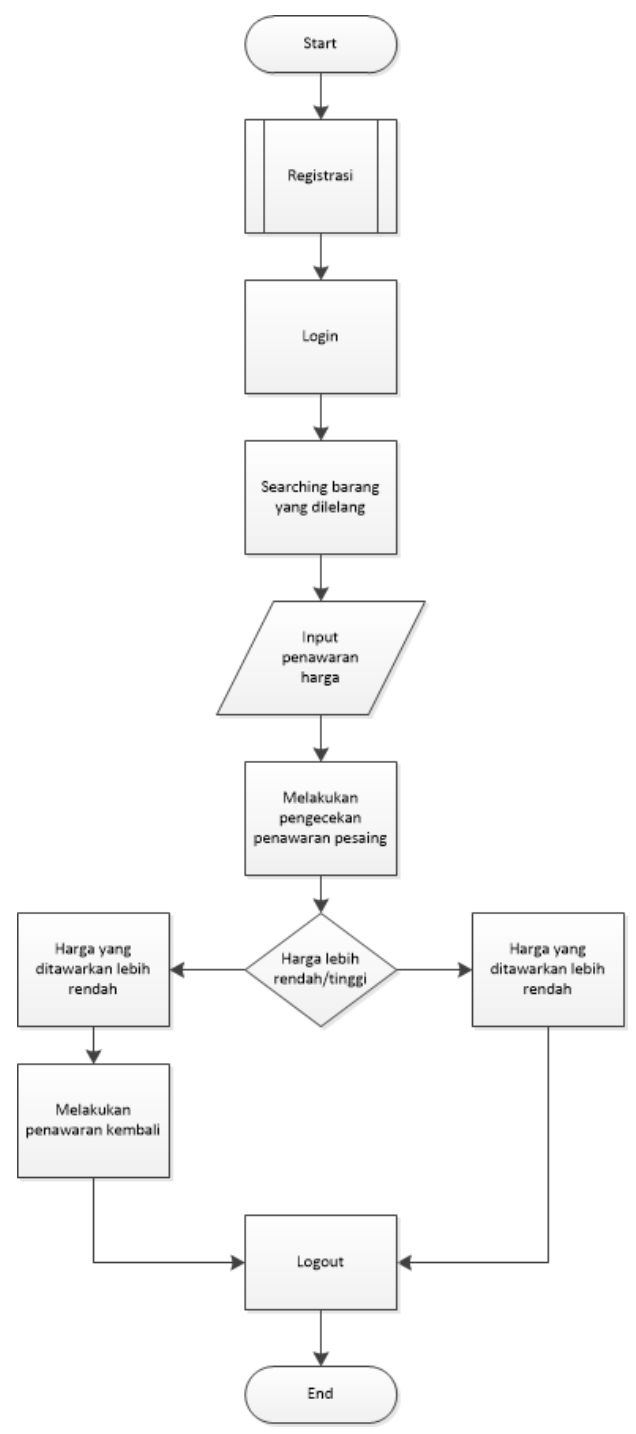

Gambar 2. Flowchart Penawar

3) Admin

Keterangan Admin :

a) Admin melakukan $\log$ in untuk menggunakan Sistem Informasi ini

b) Kemudian admin melakukan manage data user : jika barang dari pelelang terjual, maka admin melakukan delete user dan memberikan info terbaru pelelangan. Jika barang dari pelelang tidak terjual, maka admin melakukan penyesuaian dari pelelang, apakah ingin lanjut atau tidak 
c) Admin Logout untuk mengakhiri.

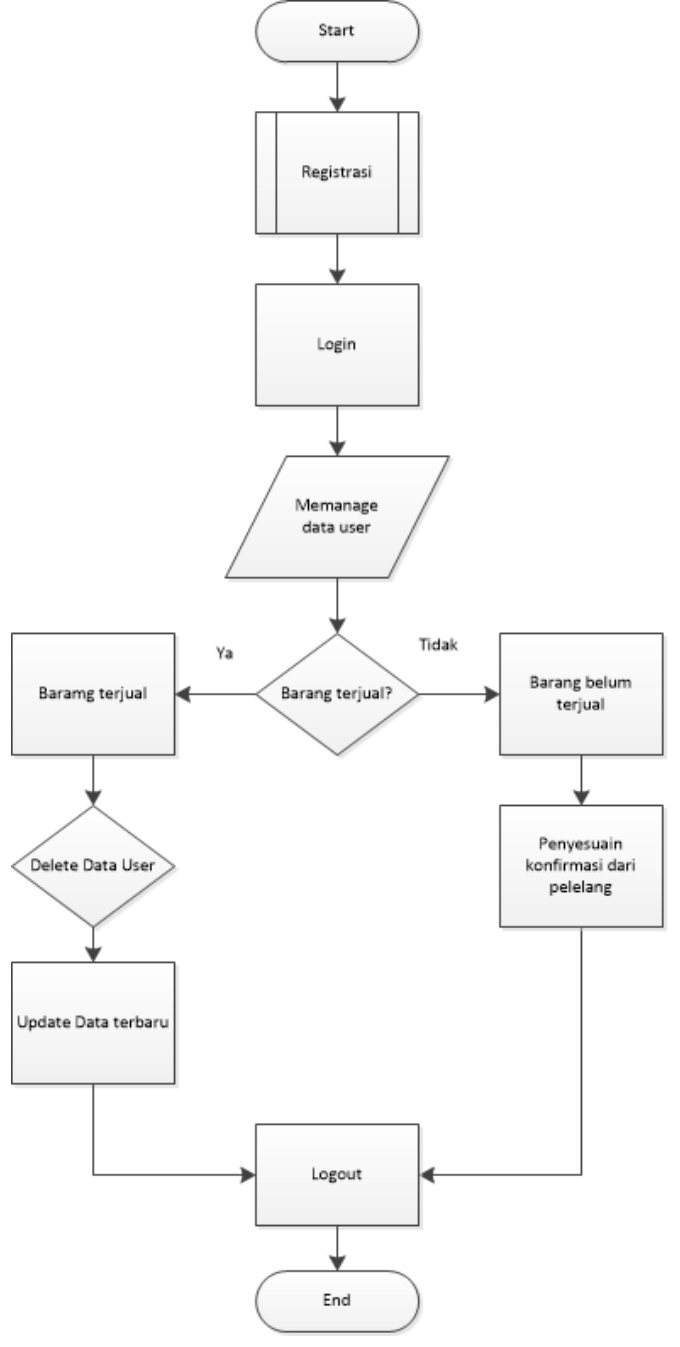

Gambar 3. Flowchart Admin

4) Tamu

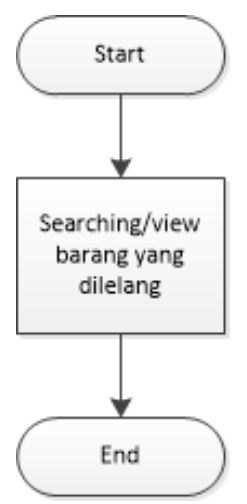

Gambar 4. Flowchart Tamu

Keterangan Tamu :

Guest hanya melakukan kegiatan statik yaitu melakukan view dan searching barang yang dilelang

D. Perancangan Basis Data

1) Desain Database

TABEL 1

KEBUTUHAN

\begin{tabular}{|l|l|l|l|}
\hline \multicolumn{1}{|c|}{ Field } & \multicolumn{1}{|c|}{ Type } & PK & Keterangan \\
\hline $\begin{array}{l}\text { kode__ } \\
\text { kebutuhan }\end{array}$ & varchar (5) & PK & $\begin{array}{l}\text { kode } \\
\text { permintaan } \\
\text { kebutuhan }\end{array}$ \\
\hline waktu_guna & date & & $\begin{array}{l}\text { tanggal } \\
\text { penggunaan }\end{array}$ \\
\hline jenis_keb & varchar (15) & & $\begin{array}{l}\text { jenis } \\
\text { kebutuhan }\end{array}$ \\
\hline nama_barang & varchar (20) & & $\begin{array}{l}\text { nama barang } \\
\text { yang } \\
\text { dibutuhkan }\end{array}$ \\
\hline jumlah & int (8) & & $\begin{array}{l}\text { jumlah barang } \\
\text { yang } \\
\text { dibutuhkan }\end{array}$ \\
\hline harga & float/double & & $\begin{array}{l}\text { keterangan barang } \\
\text { pengadaan } \\
\text { barang yang } \\
\text { dibutuhkan }\end{array}$ \\
\hline ket & text & & $\begin{array}{l}\text { spesifikasi } \\
\text { barang }\end{array}$ \\
\hline tot_nilai & varchar & & $\begin{array}{l}\text { total nilai } \\
\text { pengadaan, } \\
\text { harga } \\
\text { jumlah }\end{array}$ \\
\hline spesifikasi & mediumtext & &
\end{tabular}

TABEL 2

PENGADAAN

\begin{tabular}{|l|l|l|l|}
\hline Field & Type & PK & Keterangan \\
\hline $\begin{array}{l}\text { kode_keb } \\
\text { utuhan }\end{array}$ & $\begin{array}{l}\text { varchar } \\
(5)\end{array}$ & PK & $\begin{array}{l}\text { kode } \\
\text { permintaan } \\
\text { kebutuhan }\end{array}$ \\
\hline $\begin{array}{l}\text { kode_pen } \\
\text { gadaan }\end{array}$ & $\begin{array}{l}\text { varchar } \\
(5)\end{array}$ & $\begin{array}{l}\text { kode pengadaan } \\
\text { barang }\end{array}$ \\
\hline bidang & $\begin{array}{l}\text { varchar } \\
(15)\end{array}$ & $\begin{array}{l}\text { bidang yang } \\
\text { membutuhkan } \\
\text { pengadaan } \\
\text { barang }\end{array}$ \\
\hline tgl & date & $\begin{array}{l}\text { tanggal } \\
\text { pembuatan } \\
\text { pengadaan } \\
\text { kebutuhan }\end{array}$ \\
\hline $\begin{array}{l}\text { kisar_har } \\
\text { ga }\end{array}$ & bigint & $\begin{array}{l}\text { perkiraan harga } \\
\text { barang }\end{array}$ \\
\hline tujuan & medium & & $\begin{array}{l}\text { tujuan } \\
\text { pengadaan } \\
\text { barang }\end{array}$ \\
\hline
\end{tabular}


TABEL 3

PERKIRAAN HARGA

\begin{tabular}{|l|l|l|l|}
\hline Field & Type & PK & Keterangan \\
\hline $\begin{array}{l}\text { kode_perkir } \\
\text { aan_- } \\
\text { hrga }\end{array}$ & $\begin{array}{l}\text { varchar } \\
(5)\end{array}$ & PK & $\begin{array}{l}\text { kode dari } \\
\text { perkiraan dari } \\
\text { harga da } \\
\text { perusahaan }\end{array}$ \\
\hline sumber & $\begin{array}{l}\text { varchar } \\
(15)\end{array}$ & $\begin{array}{l}\text { bidang yang } \\
\text { membutuhkan } \\
\text { pengadaan } \\
\text { barang }\end{array}$ \\
\hline keluaran_ke & $\begin{array}{l}\text { varchar } \\
(5)\end{array}$ & $\begin{array}{l}\text { kode urutan } \\
\text { dari keluaran } \\
\text { proyek }\end{array}$ \\
\hline harga & bigint & & $\begin{array}{l}\text { perkiraan } \\
\text { harga barang }\end{array}$ \\
\hline spesifikasi & $\begin{array}{l}\text { medium } \\
\text { text }\end{array}$ & $\begin{array}{l}\text { spesifikasi } \\
\text { barang }\end{array}$ \\
\hline
\end{tabular}

TABEL 4

\begin{tabular}{|l|l|l|l|}
\multicolumn{5}{|c}{ VENDOR } \\
\hline Field & Type & PK & Keterangan \\
\hline NPWP & $\begin{array}{l}\text { varchar } \\
(15)\end{array}$ & PK & NPWP Vendor \\
\hline $\begin{array}{l}\text { nama_ven } \\
\text { dor }\end{array}$ & $\begin{array}{l}\text { varchar } \\
(10)\end{array}$ & & $\begin{array}{l}\text { nama pemilik } \\
\text { atau pimpinan } \\
\text { vendor }\end{array}$ \\
\hline $\begin{array}{l}\text { bidang_us } \\
\text { aha }\end{array}$ & $\begin{array}{l}\text { varchar } \\
(15)\end{array}$ & & $\begin{array}{l}\text { bidang usaha } \\
\text { yang dikelola } \\
\text { oleh vendor }\end{array}$ \\
\hline alamat & $\begin{array}{l}\text { varchar } \\
(25)\end{array}$ & & $\begin{array}{l}\text { alamat dari } \\
\text { vendor }\end{array}$ \\
\hline kota & $\begin{array}{l}\text { varchar } \\
(15)\end{array}$ & & $\begin{array}{l}\text { kota alamat } \\
\text { dari vendor }\end{array}$ \\
\hline telp & $\begin{array}{l}\text { varchar } \\
(13)\end{array}$ & & $\begin{array}{l}\text { nomor telepon } \\
\text { vendor yang } \\
\text { dapat } \\
\text { dihubungi }\end{array}$ \\
\hline email & $\begin{array}{l}\text { varchar } \\
(20)\end{array}$ & $\begin{array}{l}\text { alamat email } \\
\text { dari vendor }\end{array}$ \\
\hline fax & $\begin{array}{l}\text { varchar } \\
(13)\end{array}$ & $\begin{array}{l}\text { nomor fax dari } \\
\text { vendor }\end{array}$ \\
\hline pj & $\begin{array}{l}\text { varchar } \\
(25)\end{array}$ & $\begin{array}{l}\text { penanggung } \\
\text { jawab dari } \\
\text { penyedia } \\
\text { layanan barang } \\
\text { jasa }\end{array}$ \\
\hline jabatan & $\begin{array}{l}\text { enum('dire } \\
\text { ktur', } \\
\text { 'kepala') }\end{array}$ & $\begin{array}{l}\text { jabatan dari } \\
\text { penangungjaw } \\
\text { ab vendor }\end{array}$ \\
\hline & & & \\
\hline
\end{tabular}

TABEL 5

PENAWARAN HARGA

\begin{tabular}{|l|l|l|l|}
\hline Field & Type & PK & Keterangan \\
\hline NPWP & $\begin{array}{l}\text { varchar } \\
(15)\end{array}$ & & $\begin{array}{l}\text { Nomor } \\
\text { Pengguna } \\
\text { Wajib Pajak } \\
\text { Vendor }\end{array}$ \\
\hline tgl_tawar & date & & $\begin{array}{l}\text { tanggal ketika } \\
\text { melakukan }\end{array}$ \\
\hline
\end{tabular}

\begin{tabular}{|l|l|l|l|}
\hline & & & penawaran \\
\hline $\begin{array}{l}\text { kode_penga } \\
\text { daan }\end{array}$ & $\begin{array}{l}\text { varchar } \\
(15)\end{array}$ & $\begin{array}{l}\text { kode } \\
\text { pengadaan } \\
\text { yang akan } \\
\text { ditawar } \\
\text { harganya }\end{array}$ \\
\hline $\begin{array}{l}\text { nama_baran } \\
\text { g }\end{array}$ & $\begin{array}{l}\text { varchar } \\
(20)\end{array}$ & $\begin{array}{l}\text { nama barang } \\
\text { yang } \\
\text { dibutuhkan }\end{array}$ \\
\hline kisar_harga & bigint & & $\begin{array}{l}\text { perkiraan } \\
\text { harga barang }\end{array}$ \\
\hline
\end{tabular}

TABEL 6

PEMENANG

\begin{tabular}{|l|l|l|l|}
\hline Field & Type & PK & Keterangan \\
\hline NPWP & $\begin{array}{l}\text { varchar } \\
(15)\end{array}$ & & $\begin{array}{l}\text { NPWP } \\
\text { Vendor }\end{array}$ \\
\hline $\begin{array}{l}\text { kode_penga } \\
\text { daan }\end{array}$ & $\begin{array}{l}\text { varchar } \\
(15)\end{array}$ & $\begin{array}{l}\text { kode } \\
\text { pengadaan } \\
\text { yang akan } \\
\text { ditawar } \\
\text { harganya }\end{array}$ \\
\hline harga & bigint & $\begin{array}{l}\text { harga barang } \\
\text { yang telah } \\
\text { disetujui }\end{array}$ \\
\hline
\end{tabular}

TABEL 7

TABEL USER

\begin{tabular}{|l|l|l|l|}
\hline Field & Type & PK & Keterangan \\
\hline id_user & int (3) & & $\begin{array}{l}\text { nomor urut } \\
\text { user }\end{array}$ \\
\hline username & varchar (15) & & username user \\
\hline password & varchar (15) & & password user \\
\hline nama & varchar (25) & & $\begin{array}{l}\text { nama lengkap } \\
\text { user }\end{array}$ \\
\hline hakakses & $\begin{array}{l}\text { enum('admin } \\
\text { ','user') }\end{array}$ & $\begin{array}{l}\text { hak akses dari } \\
\text { pengguna } \\
\text { sistem } \\
\text { informasi }\end{array}$ \\
\hline
\end{tabular}

TABEL 8

BIDANG USAHA

\begin{tabular}{|c|c|c|c|}
\hline \multicolumn{1}{|c|}{ Field } & Type & PK & Keterangan \\
\hline $\begin{array}{c}\text { id_bidang_us } \\
\text { aha }\end{array}$ & int(3) & $\begin{array}{c}\text { nomor urut } \\
\text { bidang usaha }\end{array}$ \\
\hline bidang_usaha & $\begin{array}{c}\text { varchar } \\
(15)\end{array}$ & PK & $\begin{array}{c}\text { nama bidang } \\
\text { usaha }\end{array}$ \\
\hline skala_bidang & $\begin{array}{c}\text { varchar } \\
(10)\end{array}$ & $\begin{array}{c}\text { skala bidang } \\
\text { usaha (besar, } \\
\text { sedang, dan } \\
\text { kecil) }\end{array}$ \\
\hline keterangan & $\begin{array}{c}\text { varchar } \\
(50)\end{array}$ & $\begin{array}{c}\text { keterangan } \\
\text { mengenai } \\
\text { bidang usaha }\end{array}$ \\
\hline \multicolumn{4}{|c|}{ BABEL 9} \\
\hline Field & Type & PK & Keterangan \\
\hline id_barang & int(3) & nomor \\
\hline
\end{tabular}




\begin{tabular}{|l|l|l|l|}
\hline & & & barang \\
\hline nama_barang & $\begin{array}{l}\text { varchar } \\
(15)\end{array}$ & PK & nama barang \\
\hline harga_barang & bigint & & harga barang \\
\hline $\begin{array}{l}\text { spesifikasi_ba } \\
\text { rang }\end{array}$ & $\begin{array}{l}\text { varchar } \\
(50)\end{array}$ & $\begin{array}{l}\text { spesifikasi } \\
\text { barang }\end{array}$ \\
\hline
\end{tabular}

\begin{tabular}{|l|c|c|c|}
\multicolumn{4}{c}{ TABEL 10.} \\
\hline Field & Type & PK & Keterangan \\
\hline $\begin{array}{l}\text { id_negosiatio } \\
\text { n }\end{array}$ & int(3) & & $\begin{array}{c}\text { nomor urut } \\
\text { negosiasi }\end{array}$ \\
\hline nama & $\begin{array}{c}\text { varch } \\
\text { ar }(15)\end{array}$ & $\begin{array}{c}\text { nama yang } \\
\text { mengajukan } \\
\text { negosiasi }\end{array}$ \\
\hline topik & $\begin{array}{c}\text { varch } \\
\operatorname{ar}(15)\end{array}$ & $\begin{array}{c}\text { topik } \\
\text { negosiasi }\end{array}$ \\
\hline komentar & $\begin{array}{c}\text { varch } \\
\operatorname{ar}(50)\end{array}$ & & $\begin{array}{c}\text { komentar } \\
\text { negosiasi }\end{array}$ \\
\hline
\end{tabular}

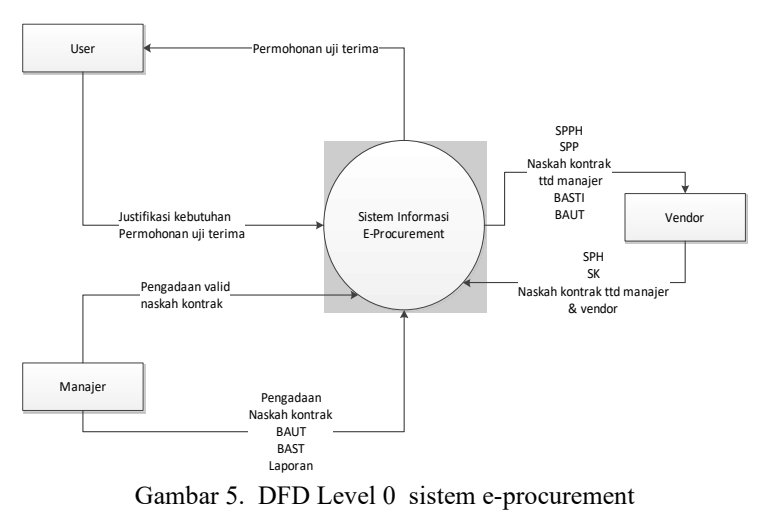

b) DFD Level 1 Admin

TABEL 11

\begin{tabular}{|c|c|c|c|}
\hline \multicolumn{4}{|c|}{ SUPPLIER } \\
\hline Field & Type & PK & Keterangan \\
\hline id_supplier & $\operatorname{int}(3)$ & & $\begin{array}{ll}\text { nomor } & \text { urut } \\
\text { supplier } & \end{array}$ \\
\hline $\begin{array}{l}\text { nama_perusa } \\
\text { haan }\end{array}$ & $\begin{array}{l}\text { varchar } \\
(15)\end{array}$ & & $\begin{array}{l}\text { nama } \\
\text { perusahaan }\end{array}$ \\
\hline alamat_per & $\begin{array}{l}\text { varchar } \\
(50)\end{array}$ & & $\begin{array}{l}\text { alamat } \\
\text { perusahaan }\end{array}$ \\
\hline email & $\begin{array}{l}\text { varchar } \\
\text { (15) }\end{array}$ & & $\begin{array}{l}\text { email } \\
\text { perusahaan }\end{array}$ \\
\hline $\mathrm{cp}$ & $\begin{array}{l}\text { varchar } \\
(20)\end{array}$ & & contact person \\
\hline
\end{tabular}

2) Entity Relationship Diagram (ERD)

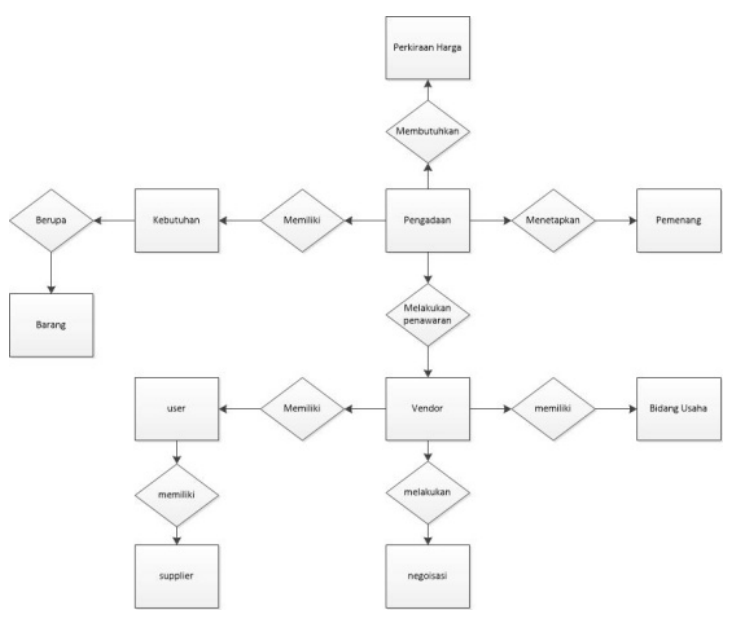

Gambar 5. Entity Relationship Diagram e-procurement

3) DFD (Data Flow Diagram)

a) DFD Level 0

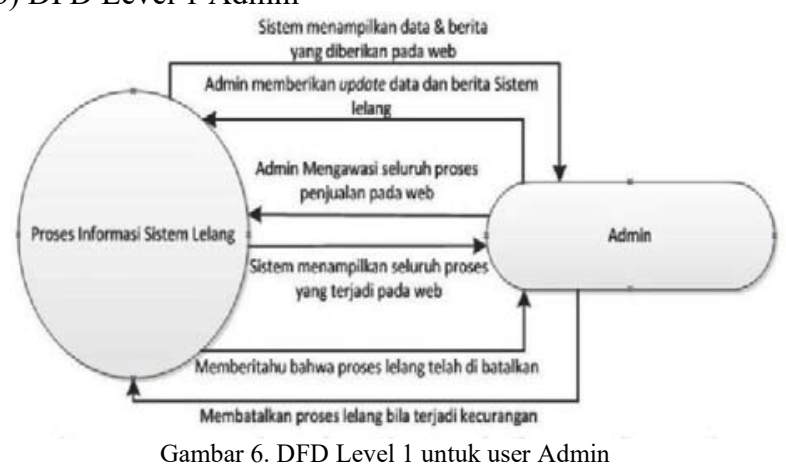

c) DFD Level 1 Pelelang

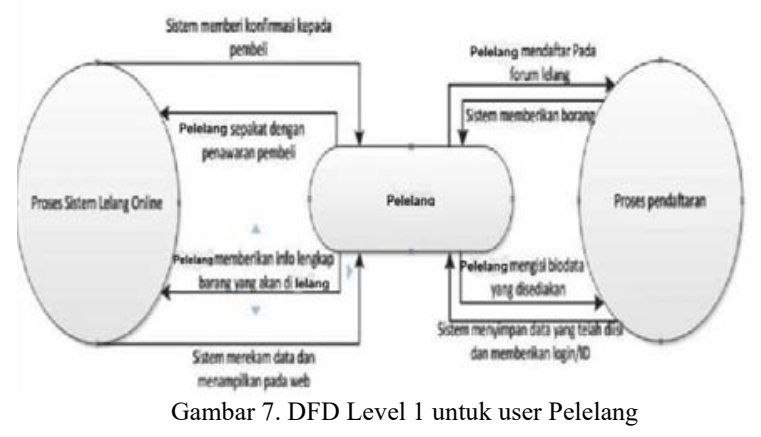

d) DFD Level 1 Penawar

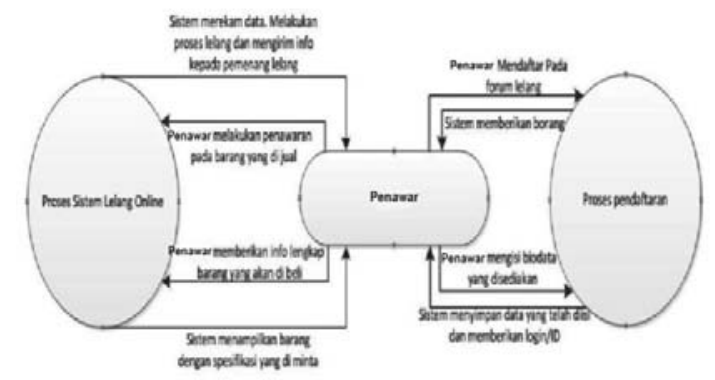


Gambar 8. DFD Level 1 untuk user Penawar

4) Desain Sistem Informasi

Rancangan desain sistem informasi dari E-Procurement terdiri dari beberapa tampilan seperti berikut :

a) Tampilan Menu Utama (Home)

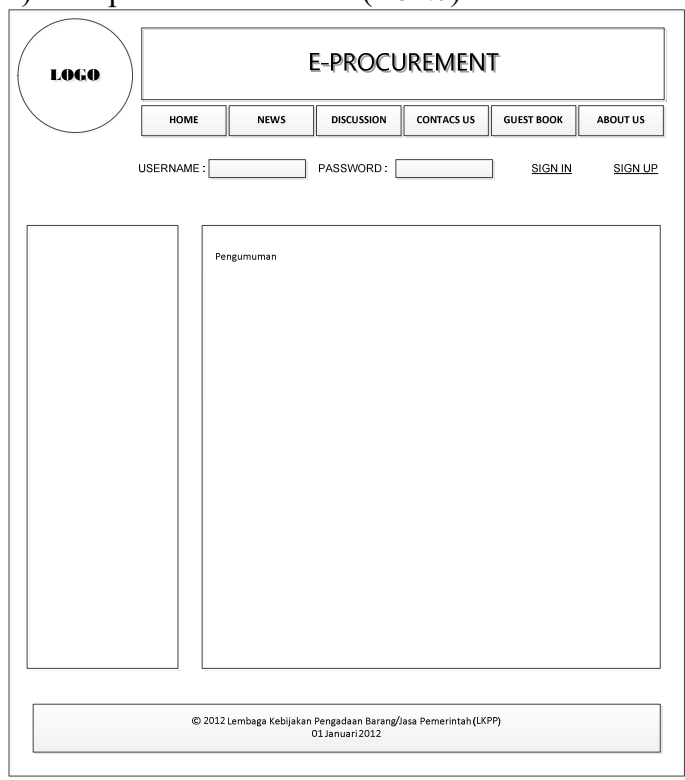

Gambar 9. Tampilan Menu Utama

Pada halaman home, sistem ini ditujukan sebagai antar muka penyambut khusus bagi pengguna dan pengunjung sistem, yaitu mengisi username dan password yang sudah memiliki validasi input untuk mengakses menu utama secara pribadi.

Sedangkan bagi pengunjung sistem, dapat mengakses menu register untuk menjadi anggota sistem, melihat berita, berdiskusi, mengisi pesan di Guest Book, dan melihat keterangan perusahaan agar kelak dapat menghubungi pihak perusahaan untuk mengadakan kontrak dan hubungan lebih lanjut. Selain itu pada menu awal terdapat juga hasil pengumuman hasil seleksi pelelangan.

b) Halaman di Antarmuka Awal

Adapun halaman rancangan layar menu yang tersedia di antar muka awal adalah sebagai berikut : Home berisi informasi - informasi umum bagi pengguna vendor, News berisi berita berita terbaru terkait vendor, Discussion sebagai tempat diskusi, contact us yang menyediakan nomor dan email yang bisa dihubungi, guest book sebagai pencatat buku tamu, dan about us.

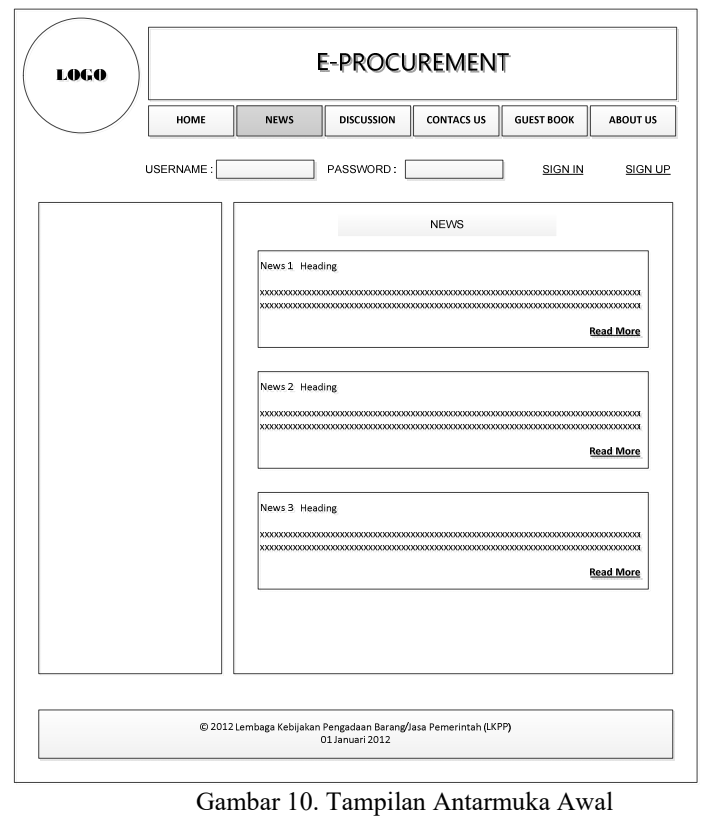

c) Halaman Vendor

Terdapat beberapa pilihan menu yang dapat diakses oleh beberapa pengguna diantara adalah ; Edit profil, Register Vendor, Term and Condition, Request Order, Negosiation Forum, Purchase Order.

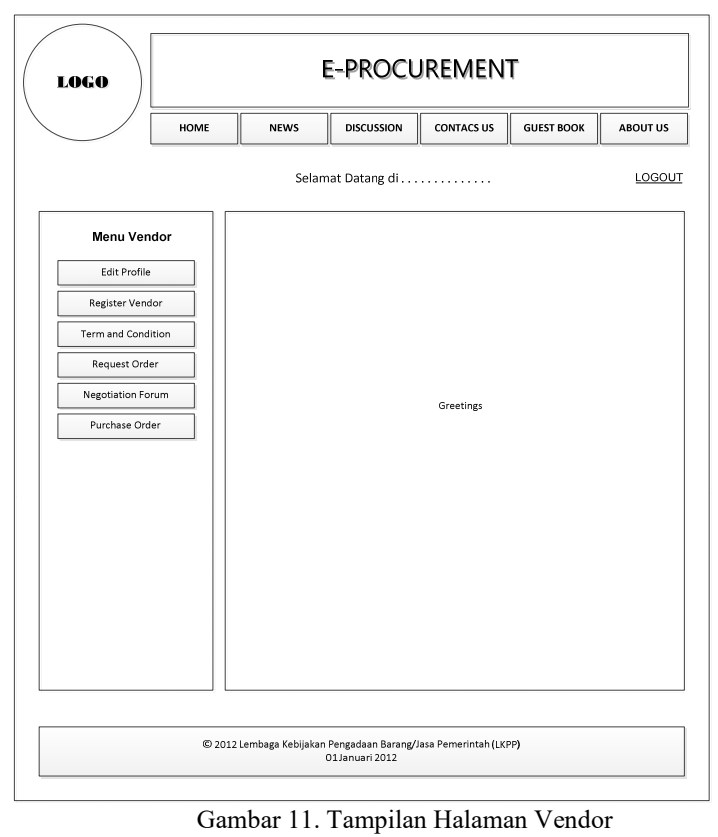

d) Halaman Administrator

Terdapat beberapa pilihan menu bagi admin diantaranya adalah sebagai berikut : Admin news, admin produk, admin request produk, admin purchase order, admin supplier. 


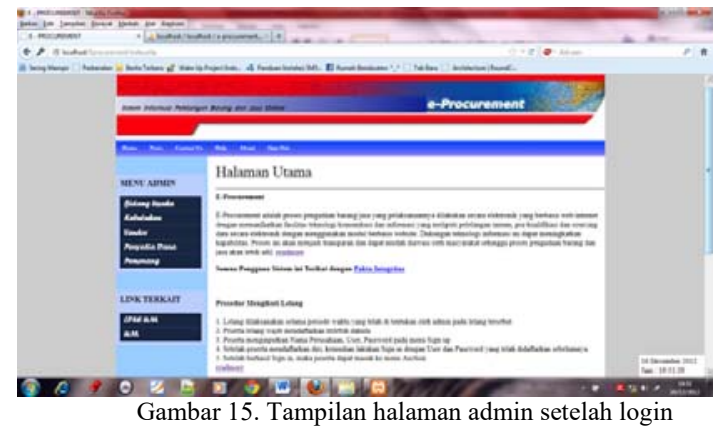

\section{KESIMPULAN}

E-Procurement adalah proses pengadaan barang/jasa yang pelaksanaannya dilakukan secara elektronik yang berbasis web/internet dengan memanfaatkan fasilitas teknologi komunikasi dan informasi yang meliputi pelelangan umum, pra-kualifikasi dan sourcing data secara elektronik dengan menggunakan modul berbasis website.

Gambar 12. Tampilan halaman Administrator

Berikut ini adalah tampilan antarmuka system informasi Eprocurement :

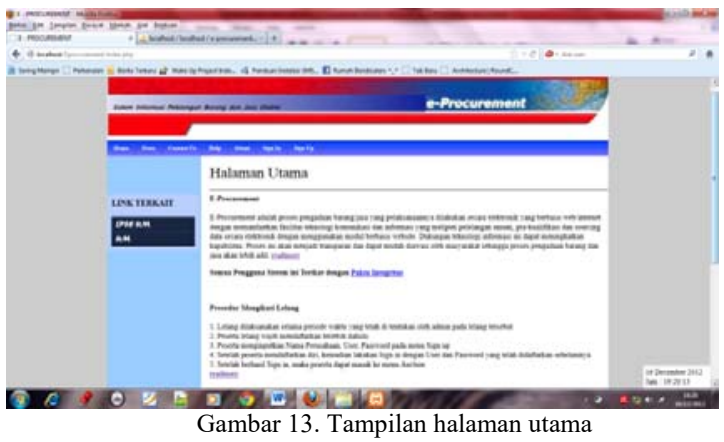

Tampilan antarmuka halaman vendor setelah login :

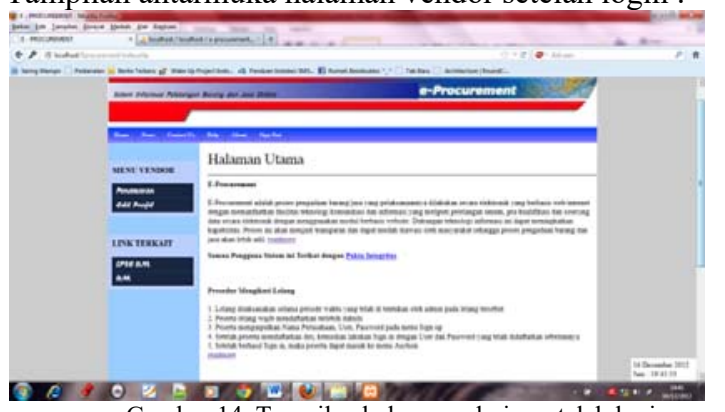

Gambar 14. Tampilan halaman admin setelah login

\section{UCAPAN TERIMA KASIH}

Ucapan terima kasih saya sampaikan kepada teman-teman yang membantu proses pembuatan sistem informasi ini, Dosen pembimbing yang mengevaluasi dan pihak lain yang tidak bisa disebutkan satu persatu serta Tim JIEET yang berkenan menerima jurnal kami. Semoga jurnal ini bermanfaat bagi peneliti lain maupun pihak yang membutuhkan.

\section{REFERENSI}

[1] Kadir, Abdul. "Tuntunan Praktis Belajar Database Menggunakan MySQL" Yogyakarta. Penerbit Andi, 2008.

[2] Kalakota, Ravi and Marcia Robinson, "E-Business 2.0 : Roadmap for Success.” Addison Wesley,Longman Inc., Cambridge, Massachussets, 2001.

[3] Madcoms, "Aplikasi Manajemen Database Pendidikan Berbasis Web Dengan PHP dan MySQL.” Yogyakarta:Penerbit Andi, 2005.

[4] Pujadi, Tri, Shandy, Dian Novita Sari, Carla Wibowo, "Perancangan Sistem E-Procurement Pada Pt. Multi Eraguna Usaha." Yogyakarta : UPN Veteran, 128,vol. 128-138, 2009.

[5] Sugiyono. "Metode Penelitian Pendidikan : Pendekatan Kuantitatif, Kualitatif, dan R\&D.” Bandung: Alfabeta, 2015.

[6] Suryatiningsih dan Muhamad, Wardani. "Courseware Politeknik Telkom mata kuliah Web Programming". Bandung: Politeknik Telkom, 2009 .

[7] Sutanta, Edhy, "Basis Data Dalam Tinjauan Konseptual." Yogyakarta : Penerbit Andi, 2011.

[8] Turban, Efraim, et al, " Electronic Commerce 2008: A Managerial Perspective." Prentince Hall, Inc., Upper Saddle River, New Jersey, 2008 . 